\title{
The influence of water vapour on the photocatalytic oxidation of cyclohexane in an internally illuminated monolith reactor ${ }^{\text {th }}$
}

\author{
Vic H.A. van Dijk ${ }^{\mathrm{a}, 1, *}$, Gideon Simmelink ${ }^{\mathrm{a}}$, Guido Mul $^{\mathrm{a}}$ \\ ${ }^{a}$ Photocatalytic Synthesis Group, Mesa+ Institute for Nanotechnology, University of Twente, P.O. Box 217, 7500 AE Enschede, The Netherlands
}

\begin{abstract}
This paper discusses effects of humidity on photocatalytic cyclohexane oxidation performed in an internally illuminated monolith reactor equipped with an immobilised layer of approximately $3 \mu \mathrm{m}$ titania (Hombikat uv100). Using dry nitrogen containing 10-20\% of oxygen, cyclohexanone is produced with high selectivity (> 90\%) over cyclohexanol. The photocatalytic monolith deactivates within 80 minutes of operation. Regeneration of activity of such deactivated monolith is possible by air treatment at $450{ }^{\circ} \mathrm{C}$.

When the applied nitrogen/oxygen gas is humidified, stable ketone production rates are obtained around $5 \cdot 10^{-6} \mathrm{~mol} \mathrm{~h}^{-1}$ at an optimised relative humidity of $65 \%$. Ketone over alcohol selectivity is lower in humidified conditions, the ratio of the cyclohexanol/cyclohexanone production rates increases from 0.4 to 1.0 as a function of increasing humidity from $30 \%$ to $90 \%$.
\end{abstract}

Rapid transients in water vapour content lead to relatively slow changes in concentration of in situ produced cyclohexanone and cyclohexanol. The observation of these changes are used to explain the effect of humidity on reactor performance.

Keywords: photocatalysis, titania, cyclohexane, humidity, adsorption

\section{Introduction}

In photocatalysis, photons activate catalysts to highly energetic states, while no additional heat is needed to supply activation energy to convert reactants. Photocatalysis is employed for contaminant removal from gases and liquids such as air and water, self-cleaning of surfaces such as glass windows, transferring solar energy into chemical energy by for example water splitting and $\mathrm{CO}_{2}$ activation. Photocatalysis has also been investigated for chemical synthesis. [1-4] In particular, photocatalysis has been shown to improve the selectivity of synthesis processes that are conventionally employed at elevated temperatures. Thermally activated consecutive and parallel reactions are suppressed at the near-ambient temperatures at which photocatalysis is carried out.

The industrial production of cyclohexanone is energy-intense. Cyclohexane is oxidised at $140-180{ }^{\circ} \mathrm{C}$ [5]. To minimise side

\footnotetext{
Notice: this is the author's version of a work that was accepted for publication in Applied Catalysis A, General. Changes resulting from the publishing process, such as peer review, editing, corrections, structural formatting, and other quality control mechanisms may not be reflected in this document. Changes may have been made to this work since it was submitted for publication. A definitive version was subsequently published in Applied Catalysis A, General, [470, pp. 63-71 (30 January 2014)] doi:10.1016/j.apcata.2013.10.035

* Corresponding author, phone +31 53489 3175, fax +31 534892882

Email addresses: v.h.a.vandijk@utwente.nl (Vic H.A. van Dijk), gsimmelink@gmail.com (Gideon Simmelink), g.mul@utwente.nl (Guido Mul)

${ }^{1}$ Present address: Soft Matter, Fluidics \& Interfaces Group and Membrane Science \& Technology Group, Mesa+ Institute for Nanotechnology, University of Twente, P.O. Box 217, 7500 AE Enschede, The Netherlands
}

product formation, the conversion is kept low. Unconverted cyclohexane is separated from the reaction mixture and is recycled. Cyclohexanol and other byproducts are converted into cyclohexanone, again after energy intensive separation processes.

Oxidation of liquid cyclohexane by using an uv-illuminated titania photocatalyst around room temperature promises improved selectivity and overall energy savings. The following aspects have been addressed in the literature:

- modification of the $\mathrm{TiO}_{2}$ photocatalyst [6-15]

- optimisation of reactant/product adsorption/desorption on/ from the photocatalyst $[9,16,17]$, e.g. by addition of water $[18,19]$ or solvents [19-21]

- regeneration of deactivated photocatalysts [22]

- optimisation of the operation temperature [23]

- optimisation of (the wavelength of) the irradiance [15, 24]

- optimisation of the oxygen concentration [21]

- optimisation of the reactor design [25]

- mechanistic understanding [26, 27] to allow rational design of improved catalyst materials

Most of the studies indicated above employed slurry reactors to evaluate catalytic performance. Immobilisation of the photocatalyst eliminates the need for filtration of the reactor effluent 
and principally enables continuous operation of the photocatalyst. Various photocatalytic reactor concepts using a monolith (channel diameter $>2 \mathrm{~mm}$ ) and/or fibres have been proposed to immobilise titania:

- an internally illuminated monolith reactor (IIMR) [28] that contains a monolith onto which the photocatalyst is immobilised (coated). A favourable surface/volume ratio is achieved this way while eliminating the need for photocatalyst recovery. Side-light emitting fibres continuously illuminate the photocatalyst that is coated onto the walls of the monolith channels.

- uv-transparent monoliths [29, 30] to allow external illumination by for example the sun, thus reaching a large surface of immobilised catalyst without suffering from shadow effects

- reticulated foam monoliths [31] in order to enhance mass transfer (compared to honeycomb monoliths) by the random, tortuous nature of the foam

- optical fibre reactors [32-36] to increase the illuminated surface area of immobilised catalyst

- photonic band-gap (inverse opal) $\mathrm{TiO}_{2}$, i.e. "photonic crystals", coated onto fibres [37] showing an increased photonic efficiency

Here, we further discuss the internally illuminated monolith reactor (IIMR). Experimental data on monoliths for purification of water [31, 32] and air [38-41] are available, but a detailed systematic evaluation of parameters affecting the performance in selective oxidation has not been reported so far. Du et al. [28] have published the results of only one experiment using the IIMR, in combination with the photocatalyst anatase titania Hombikat uv100 for production of cyclohexanone from cyclohexane. A significant initial rate was reported, which rapidly decreased. An explanation for this trend was not provided. Carneiro et al. [22] have also published a result on the performance of a Solaronix $\mathrm{TiO}_{2}$ photocatalyst coated onto a silicacoated cordierite monolith. The silica was used to prevent accumulation of (inactive) $\mathrm{TiO}_{2}$ in the macropores of the cordierite. This study does not provide information on the effects of process parameters, such as humidity, on the reaction efficiency in the monolith and neither on deactivation aspects.

Water vapour has been reported to affect the performance of photocatalytic cyclohexane oxidation in slurry reactors $[18,19]$, by altering adsorption/desorption behaviour and/or by forming hydroxyl radicals.

The herein presented study provides novel detailed information on the performance of the IIMR in photocatalytic cyclohexane oxidation using titania Hombikat uv100, and specifically addresses the influence of water vapour on the performance.

\section{Experimental}

All chemicals used in this work were obtained from SigmaAldrich and used as received (unless otherwise stated). Anatase

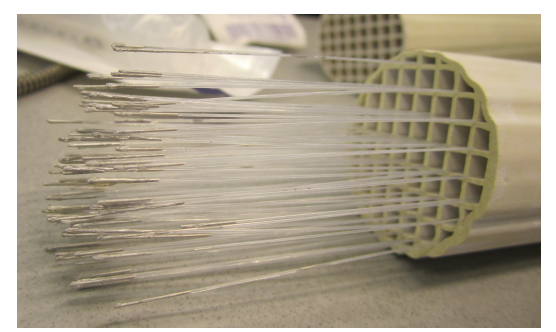

Figure 2: Photograph of side-light emitting fibres inserted into the monolith. The aluminium coating of the end of the fibres is visible at the left side (Section 2.2).

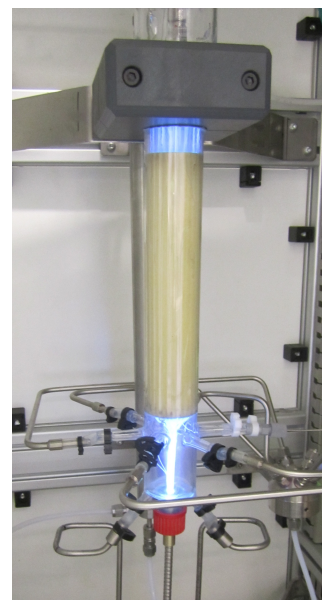

Figure 3: Photograph of the reactor vessel of the IIMR while in illuminated operation.

titania Hombikat uv100 was kindly provided by Sachtleben, and also used as received.

\subsection{Internally illuminated monolith reactor system}

The internally illuminated monolith reactor (IIMR) developed by $\mathrm{Du}$ et al. [28] was used in this work, see Figure 1 for a schematic diagram. This reactor consists of a glass reactor vessel containing a titania-coated monolith of about $23 \mathrm{~cm}$ long and $4.2 \mathrm{~cm}$ in diameter. For illumination of the photocatalyst that was coated onto the monolith walls, side-light emitting fibres were inserted into the monolith channels from the bottom of the reactor vessel, see Figure 2 for a photograph. Liquid cyclohexane (0.8-1.0 L, dried overnight by addition of $100 \mathrm{~g} 4$ $\AA$ molecular sieve [4-8 mesh] to $5 \mathrm{~L}$ of cyclohexane) was recirculated from a $1 \mathrm{~L}$ storage tank over the reactor using a gear pump. A nozzle sprayed cyclohexane on top of the monolith channels. Liquid samples were taken from the storage vessel using a tube connected to a $10 \mathrm{~mL}$ plastic syringe. A water bath kept the storage vessel at a constant temperature of around 25 ${ }^{\circ} \mathrm{C}$. Around $0.02 \mathrm{~mL}$ of hexadecane was added to the storage vessel to estimate the evaporation of cyclohexane from the IIMR by comparing the hexadecane concentration before and after operation (see Appendix B.3 for more information). See Figure 3 for a photograph of the reactor vessel of the IIMR while in illuminated operation. 


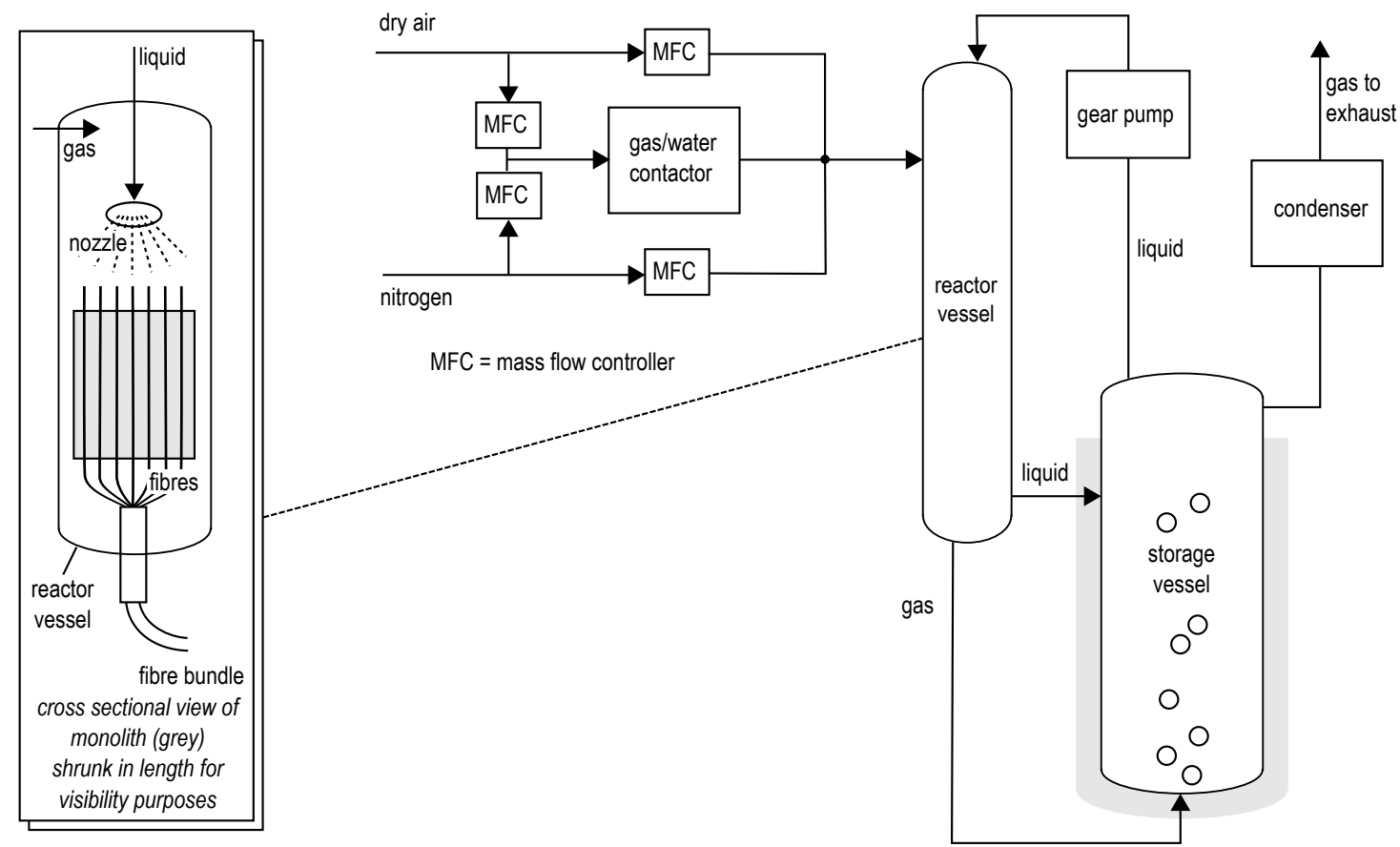

Figure 1: Schematic diagram of the internally illuminated monolith reactor system (IIMR). The storage vessel is maintained at constant temperature by a water bath (grey-coloured area). A cross-sectional zoom of the reactor including monolith and fibres is displayed at the left side of the figure. 
A mixture of water vapour, air and nitrogen was fed to the reactor vessel from the top. The composition of this gas mixture was controlled using four mass flow controllers (Brooks 5850S). The air that was fed to the setup was dried by a Drierite ${ }^{\circledR}$ gas-drying unit ${ }^{2}$ (not shown in Figure 1). Part of the air and nitrogen flows can be directed to a flask filled with water, where the gases bubble through. Part of the gas stream was thus humidified. A relative humidity sensor (Sensirion SHT71) determined the humidity of the gas mixture entering the reactor. After passing through the reactor vessel, the gas flow entered the storage vessel from the bottom and bubbled through cyclohexane. A tap water cooled condenser was located just before the gas exhaust to minimise the loss of cyclohexane.

A PC running Labview 2010 controlled the gear pump and the mass flow controllers. Temperature sensors (K-type thermocouples) were located at the top and bottom of the reactor vessel and in the storage vessel. Reactor conditions (temperatures, flows) were logged by the Labview software. The reactor was operated at atmospheric pressure.

We ensured that enough ventilation around the reactor system was available to stay below the explosion limits of cyclohexane (1.2-8.4 v\%) at all times.

\subsection{Lamp and fibres}

Tip-coated side-light emitting fibres (SpectraPartners) were used to illuminate the channels of the monolith contained by the IIMR. Each fibre had been coated at the end with aluminium to reduce emission from the tip as much as possible (Figure 2). The bundle of side-light emitting fibres was connected to an extension fibre bundle that in turn was connected to a $100 \mathrm{~W}$ high pressure mercury lamp system (HP-100 from Dr. Gröbel, containing an Osram HBo R 103w/45 lamp). The illumination could be dimmed by varying the distance between the extension fibre bundle and the collection of fibres inserted into the monolith.

Irradiance was determined using a photospectrometer (USB 4000 from Ocean Optics, configured for a wavelength range of 220.75-40 $\mathrm{nm})$. The photospectrometer was calibrated radiometrically using a calibration lamp (Ocean Optics DH-2000-CAL). Light emitted by the fibres was collected using a cosine corrected irradiance probe (cc-3-uv from Ocean Optics). A holder made from black plastic was designed for probe and fibre to accurately analyse a well-defined part of the fibre [42].

A spectrum of the light irradiating from the extension fibre bundle is shown in Figure 4. A qualitative spectrum in the wavelength range of 300-700 $\mathrm{nm}$ was also obtained (Appendix A.1)

Irradiance emitted at $7 \mathrm{~cm}$ from the end of a used, dirty sidelight emitting fibre connected via the extension fibre bundle to the HP-100 mercury lamp was determined. Irradiance amounted $1 \cdot 10^{-4} \mathrm{~W} \mathrm{~m}^{-1}$ fibre for the wavelength range of 230-388 $\mathrm{nm}$. Measurement of irradiance at the start of the fibre yielded double values, which is in agreement with the observations of Du et al. [28]. Taking the average for the whole fibre yields

${ }^{2}$ Drierite ${ }^{\circledR}$ consists for $98 \%$ of the drying agent calcium sulphate $\left(\mathrm{CaSO}_{4} \cdot 0.5 \mathrm{H}_{2} \mathrm{O}\right)$, and for $2 \%$ of the moisture indicator cobalt dichloride $\left(\mathrm{CoCl}_{2}\right)$.

\begin{tabular}{ll} 
Material & $\begin{array}{c}\text { Table 1: Monolith characteristics } \\
\text { Cordierite }\end{array}$ \\
\hline Type & Cylinder \\
\hline Manufacturer & Corning \\
\hline Length & $22 \mathrm{~cm}$ \\
\hline Diameter & $42.8 \mathrm{~mm}$ \\
\hline Channel type & Square \\
\hline Channel side length & $4 \mathrm{~mm}$ \\
\hline Channel wall thickness & $1 \mathrm{~mm}$ \\
\hline
\end{tabular}

$3 \cdot 10^{-5} \mathrm{~mol} \mathrm{~h}^{-1}$ as estimation for the total amount of photons (assumed wavelength $300 \mathrm{~nm}$ ) emitted by the 100 fibres. Since the illuminated surface area of the monolith was estimated at $0.16 \mathrm{~m}^{2}$, irradiance on this catalytic surface is calculated at 1.9 . $10^{-4} \mathrm{~mol} \mathrm{~h}^{-1} \mathrm{~m}^{-2}$.

This value is about ten thousand times lower than the maximum irradiance for the linear dependency of reaction rate $\left(2.3 \mathrm{~mol} \mathrm{~h}^{-1} \mathrm{~m}\right.$ assuming photons of $300 \mathrm{~nm}$ ) [43]. Thus, we expected that the performance of the IIMR was limited by irradiance. Furthermore, determined irradiance was a factor thousand smaller than the irradiance reported by $\mathrm{Du}$ et al. [28], possibly due to an inferior light connection and the use of the fibres in previous experiments causing fouling.

\subsection{Quantitative analysis by gas-liquid chromatography}

An Agilent 7820A gas-liquid chromatograph (GC) was used to determine the concentrations of cyclohexanone, cyclohexanol and hexadecane in cyclohexane as sampled from the IIMR setup. The GC was equipped with a capillary column HP-5 from Agilent $^{3}$ and a flame ionisation detector (FID). An automated liquid sampler (Agilent ALs 7693A) injected $1 \mu \mathrm{L}$ onto the column, using a $10 \mu \mathrm{L}$ standard syringe. The aLs used cyclohexane for

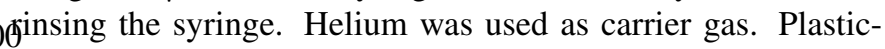
capped $2 \mathrm{~mL}$ glass vials from Chromacol were used to collect and analyse liquid samples of $1 \mathrm{~mL}$.

We prepared standard solutions containing all three components (cyclohexanone, cyclohexanol and hexadecane) in cyclohexane and analysed these to determine optimal Gc settings, GC column temperature program and response factors (see [42] and Appendix B.1 for more information). The gas-liquid chromatograph needed in total $40 \mathrm{~min}$ to analyse one sample.

Samples taken from the IIMR were analysed by gas-liquid chromatography the same day in duplicate, in a randomised order. See Appendix B.2 for more information.

\subsection{Monolith}

The characteristics of the monolith are summarised in Table 1. A top view of the monolith is shown in Figure 5. We coated anatase titania (Hombikat uv100) onto the cordierite monolith as follows.

\footnotetext{
${ }^{3}$ Column length $30 \mathrm{~m}, 0.320 \mathrm{~mm}$ diameter, $5 \%$ phenyl methyl siloxane film $0.25 \mu \mathrm{m}$, part no. $19091 \mathrm{~J}-413$
} 


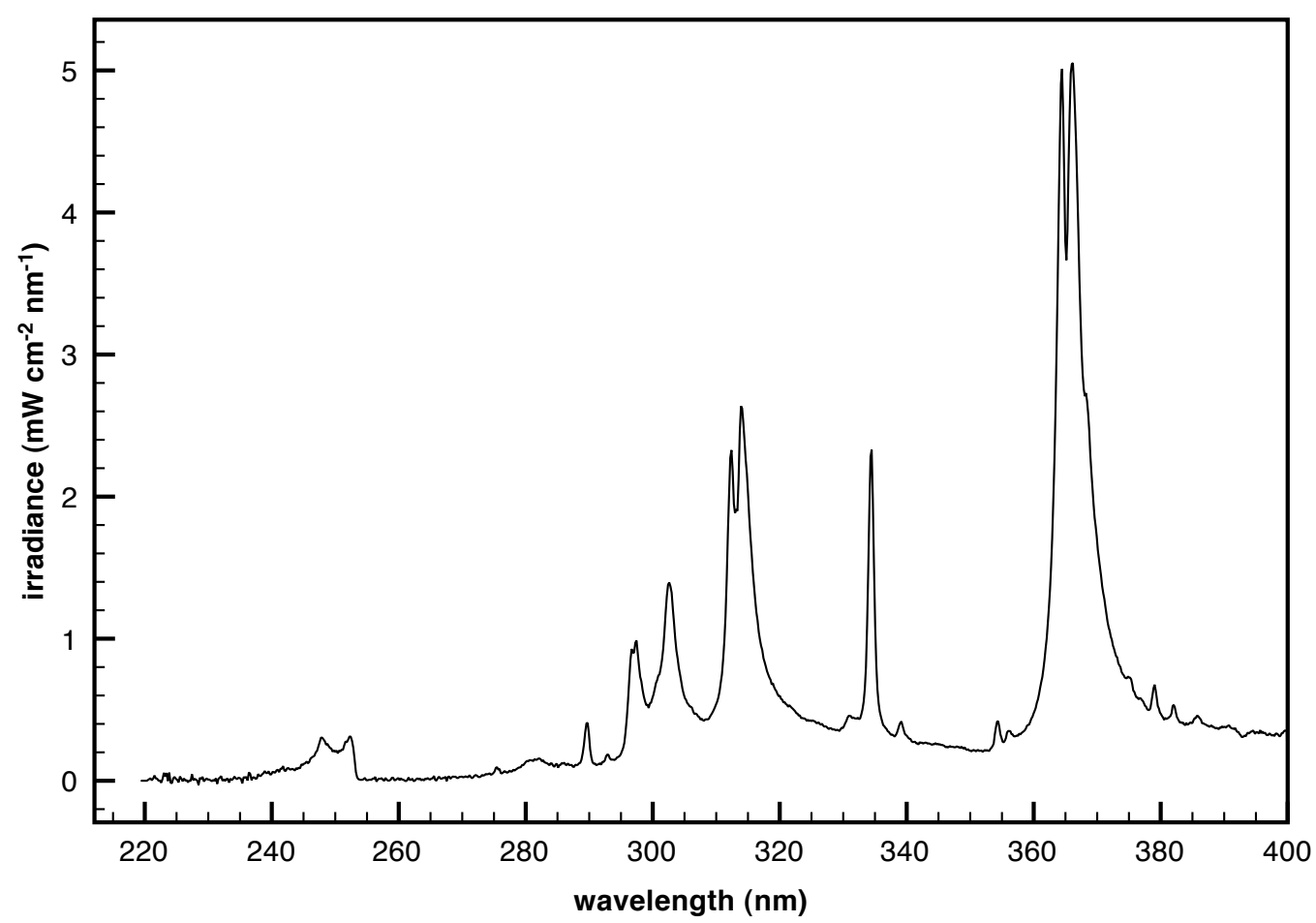

Figure 4: Irradiance as a function of wavelength $(220-400 \mathrm{~nm})$ of the light exiting the extension fibre bundle connected to the mercury lamp system. The probe was held at approximately $1 \mathrm{~cm}$ from the end of the extension fibre bundle.

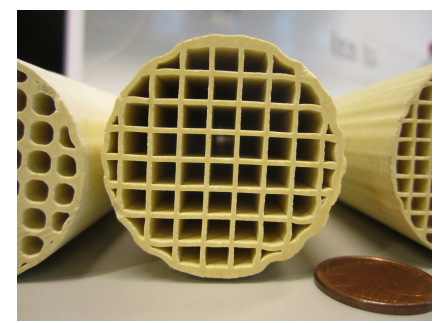

Figure 5: Top view of the monolith.

\subsubsection{Preparation of the coating solution}

The coating procedure was inspired by previous work [22, 28]. $45 \mathrm{~mL}$ titanium(Iv) isopropoxide (Ti $\left.\left[\mathrm{OCH}\left(\mathrm{CH}_{3}\right)_{2}\right]_{4}\right)$ was slowly added to $500 \mathrm{~mL}$ of demineralised water while stirring at $40{ }^{\circ} \mathrm{C}$. The addition speed was around $0.5 \mathrm{~mL} \mathrm{~min}^{-1}$. The aqueous solution of titanium(Iv) isopropoxide was kept at 40 ${ }^{\circ} \mathrm{C}$ using a heating plate equipped with thermostat.

$5 \mathrm{~mL}$ of nitric acid was added drop by drop with a Pasteur pipette to catalyse the hydrolysis reaction. The resulting solution that contains white flakes was stirred for at least 16 hours at $80{ }^{\circ} \mathrm{C}$. Around $100 \mathrm{~mL}$ water was added to prevent evaporation of all liquid during these 16 hours.

$100 \mathrm{~g}$ Hombikat uv100 was added to the white, now homogeneous solution, and stirred vigorously using a hand blender (Philips HR $1363600 \mathrm{~W}$ ) for $15 \mathrm{~min}$.

\subsubsection{Coating the monolith}

The monolith was dried at $150{ }^{\circ} \mathrm{C}$ in a furnace for several hours, prior to coating. The monolith was inserted into a $500 \mathrm{~mL}$ glass cylinder after it was cooled down, and the coating mixture was added to the cylinder until the monolith was fully submerged. During 10 min of contact between monolith and coating mixture, we pulled out the monolith somewhat and pushed back repeatedly to facilitate mixing of the coating solution and flow of the liquid into the channels. For another $10 \mathrm{~min}$ the monolith was submerged the other way down, to minimise uneven partitioning of the coating.

Immediately after taking out the monolith from the coating solution, it was held horizontally, while continuously rotating the monolith around its longest axis to prevent the coating solution from accumulating. Pressurised air was used to remove excessive liquid from the monolith channels. Hot air from a hairdryer (Principal A168 $2000 \mathrm{~W}$ ) was used to dry the monolith further.

Once the coating had been applied and the monolith showed no visible liquid, calcination was performed at $450{ }^{\circ} \mathrm{C}$ for 15 min (heating rate $40{ }^{\circ} \mathrm{C} \mathrm{min}^{-1}$ ) in a furnace. Once cooled down, the monolith was dipped again in the coating solution and the other steps of the coating procedure were repeated. The coating procedure was carried out three times in total, to obtain a layer thickness of around $27 \mu \mathrm{m}$, as reported by Du et al. [28].

\subsection{Operation of the IIMR}

The following procedure was carried out to test the photocatalytic activity of the titania-coated monolith in the internally illuminated monolith reactor (IIMR).

The liquid temperature was kept constant around $25^{\circ} \mathrm{C}$, unless otherwise stated. The liquid flow was $1.6 \mathrm{~L} \mathrm{~min}^{-1}$ (pump setting $3000 \mathrm{rpm}$ ). By varying this liquid flow it was determined 
that liquid mass transfer limitations were absent [42]. The total liquid volume at the start of each session was kept between 0.8 and $1 \mathrm{~L}$. Gas humidity was varied throughout the experiments, the total dry gas flow was kept constant around $200 \mathrm{~mL} \mathrm{~min}^{-1}$, and the dry air/nitrogen ratio was around 50/50, unless otherwise stated.

In dry conditions, after approximately $80 \mathrm{~min}$ of illumination (see Section 3.2), the monolith shows no production of cyclohexanone or other components anymore. Whenever required, the monolith was removed from the IIMR, dried and treated in a furnace $\left(40 \mathrm{~K} \mathrm{~min}^{-1}\right.$ ) at $450{ }^{\circ} \mathrm{C}$ for $15 \mathrm{~min}$ under static air, for regeneration.

\section{Results and discussion}

\subsection{Morphology of the $\mathrm{TiO}_{2}$ coating}

A cross-sectional view of the coating of strongly agglomerated anatase titania particles on the surface of the cordierite monolith is shown in Figures 6 and 7. The thickness of the layer is estimated to be in the order of 2 to $3 \mu \mathrm{m}$ (Figure 6), sufficient to fully absorb the light in the applied illumination conditions. Figure 7 demonstrates that the coating is rather homogeneous, and that the applied coating procedure prevents accumulation of $\mathrm{TiO}_{2}$ in specific domains of the cordierite support.

\subsection{Performance in dry conditions}

Figure 8 shows the liquid bulk cyclohexanone production in the course of time of three characteristic IIMR sessions (see Table 2 for conditions). The graph shows that a freshly coated monolith (squares) produces liquid bulk cyclohexanone under dry conditions from the start of illumination at 0 min. After 80 min, the production ceases. After $100 \mathrm{~min}$, even a decrease in liquid bulk cyclohexanone concentration is determined (see the insert of Figure 8).

Subsequently, the liquid product mixture was replaced by fresh cyclohexane. Cyclohexanone was found present in the liquid bulk at the start of the consecutive session, probably because of desorption from the monolith surface. No additional production of cyclohexanone can be observed during the period of illumination (Figure 8, session 2, circles). Quite the contrary: some consumption can be noticed. This is likely due to physical (re-)adsorption of cyclohexanone onto the titania surface of the deactivated monolith upon illumination, see Section 3.3.1. The observed amounts of decrease in bulk concentration are realistic for adsorption, when compared to for example adsorbed amounts determined by attenuated total reflectance Fourier transform infrared spectroscopy (ATR-FTIR) [27].

After thermal regeneration, activity under dry conditions was restored, and a production profile similar to the fresh monolith was obtained (not shown) [42]. We propose that the monolith deactivates under dry conditions due to inhibition of active sites by reaction products (cyclohexanone, cyclohexanol, carboxylates and carbonates). Heating the monolith in air will remove these reaction products, including carboxylates and carbonates, thereby restoring photocatalytic activity.
Carneiro et al. [22] were not able to observe activity of titania Hombikat uv100 powder, following use in slurry conditions at relatively high light intensity and consecutive heat treatment at $400{ }^{\circ} \mathrm{C}$ for $1 \mathrm{~h}$ in air. The successful regeneration observed for the monolith in the present study might be due to the higher temperature used for regeneration. Furthermore, due to the applied low light intensity, the nature of the deactivating species might be different (less stable against thermal oxidation).

\subsection{Effects of humidified gas flow}

In the following paragraphs we will discuss the increased production, enhanced stability, and changes in selectivity as a function of humidity.

\subsubsection{Increased production and prevention of deactivation}

Under humidified gas flow (relative humidity $>20 \%$ ), no deactivation was observed for as long as seven hours [42]. This is demonstrated by session 19 (triangles, Figure 8). The period is preceded by a slightly higher rate in the initial stages of the experiment. The higher initial rate is due to desorption of cyclohexanone produced in experiments prior to session 19 (at lower humidity levels than the $52 \%$ of session 19), initiated by the relatively high humidity provided. After $150 \mathrm{~min}$, water adsorption equilibrium has presumably been reached, yielding a lower, but stable cyclohexanone production rate.

The hypothesis of cyclohexanone desorbing as a result of humidity is supported by the following experiment. Figure 9 shows transients in cyclohexanone and cyclohexanol concentrations as a function of transients in humidity ranging from 0 to $80 \%$ in dark conditions. Before this experiment, the monolith was applied in multiple illumination experiments in humid conditions, the last at approximately $50 \%$ humidity. The first transient to dry conditions clearly results in a linear decrease in cyclohexanone and cyclohexanol concentrations, suggesting adsorption of the products onto the monolith structure. Increasing the humidity to $80 \%$ subsequently results in desorption, at similar apparent rate as the adsorption process. The response of the monolith to humidity changes is slow. Surprisingly, a second dry-wet cycle showed faster transients in concentration: the re-adsorption of both products of cyclohexane oxidation is faster, but also the subsequent rate of desorption. Apparently illumination changes the adsorption behaviour of $\mathrm{TiO}_{2}$.

Some other experiments [42] show that a monolith that has a history of uv-illumination adsorbs more cyclohexanone from the liquid bulk than a monolith that has not seen uv or longer ago. This change in adsorption behaviour due to illumination is in line with other research on cyclohexanone desorption [16], and with the known photo-induced hydrophilic effect [2] (also known as "photoinduced superhydrophilicity" [1]).

Note that despite illumination history, a regenerated monolith produces cyclohexanone immediately (without an induction period) for 80 minutes under dry conditions. Therefore we think the heat treatment resets adsorption behaviour of the titania surface. 


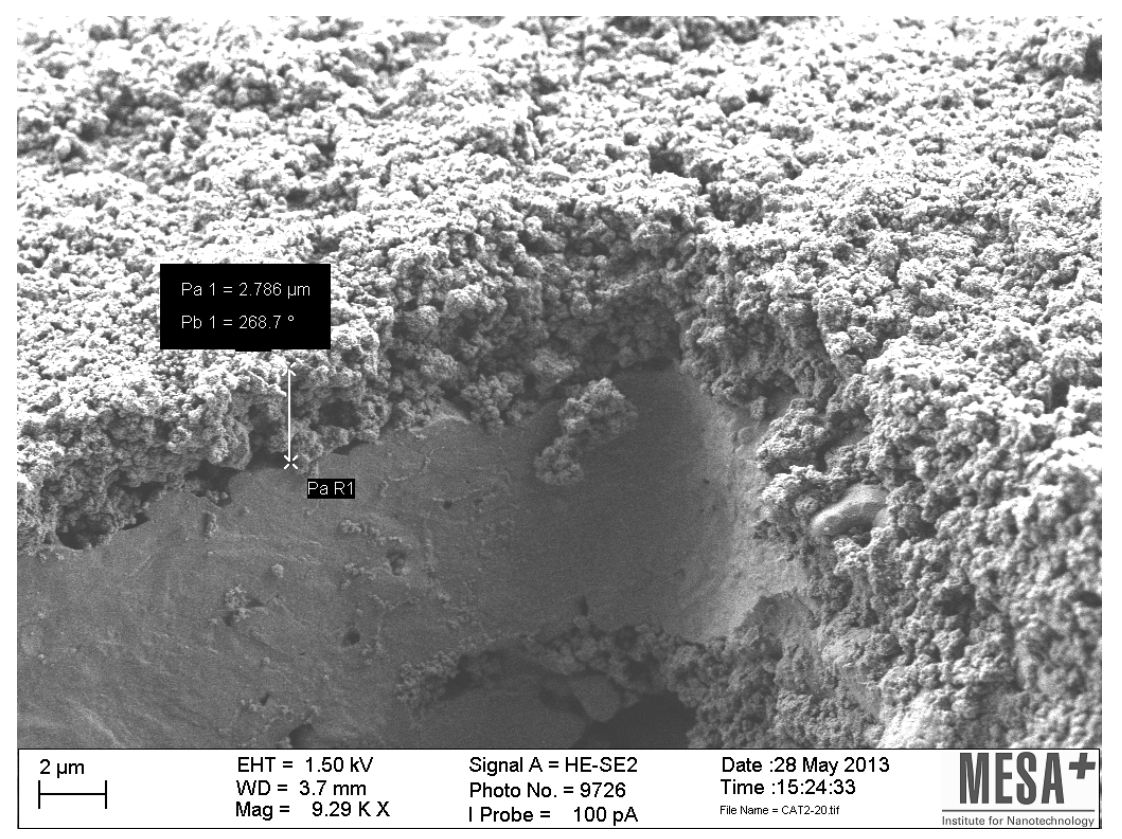

Figure 6: Sem image of the agglomerated layer of the titania particles.

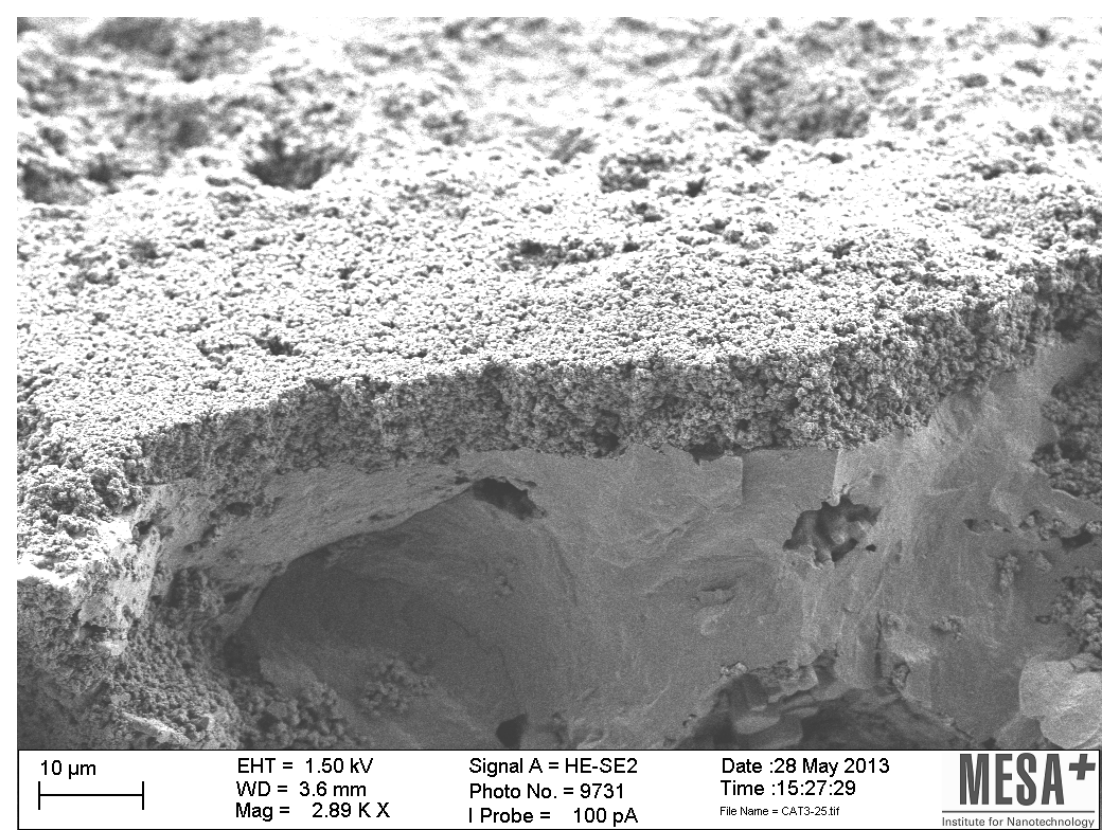

Figure 7: Sem image of the agglomerated layer of the titania particles.

Table 2: Reactor conditions for reactor sessions 1, 2 and 19.

\begin{tabular}{lrrrr} 
Condition & Unit & Session 1 & Session 2 & Session 19 \\
\hline \hline Liquid temperature & ${ }^{\circ} \mathrm{C}$ & 25 & 26 & 25 \\
\hline Air flow & $\mathrm{L} \mathrm{min}^{-1}$ & 4.649 & 0.312 & 0.112 \\
\hline Nitrogen flow & $\mathrm{L} \mathrm{min}^{-1}$ & 0 & 0.333 & 0.101 \\
\hline Relative humidity & $\%$ & 0 & 0 & 52 \\
\hline Monolith origin & n/a & freshly coated & from session 1 & used in preceding sessions \\
\hline
\end{tabular}




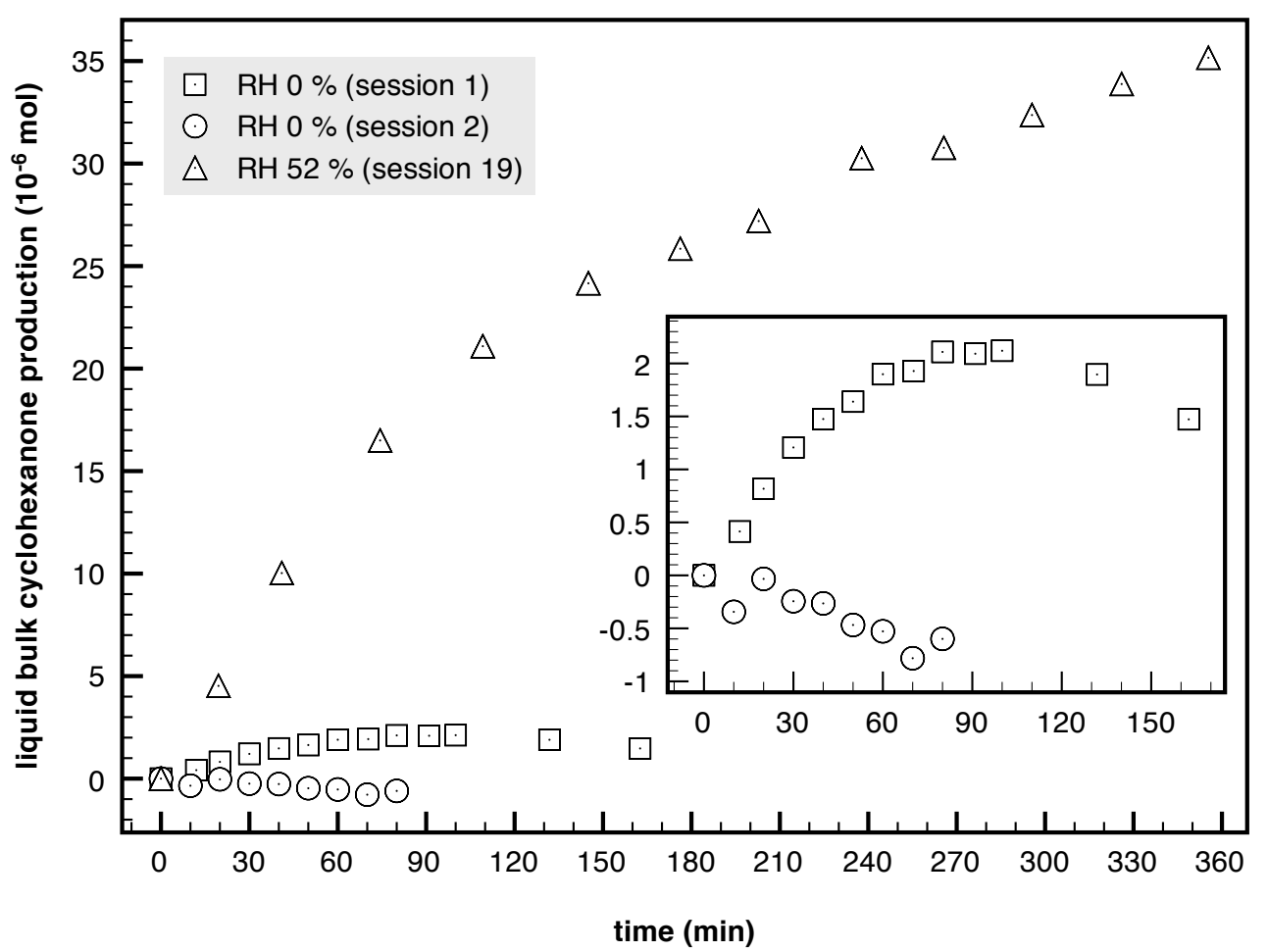

Figure 8: Liquid bulk production of cyclohexanone versus course of time of three sessions conducted using the IIMR.

The inset shows sessions 1 and 2 in more detail (the same units apply to its axes). Note that the production is cumulative, and defined to be 0 at time $=0$. The production is corrected for the effect of evaporation of cyclohexane (Equation B.3).

The IIMR including the monolith was dried overnight before session 19 started.

Additionally, one long illuminated session was carried out around $4.2 \%$ relative humidity. As expected, this session started with the consumption of both cyclohexanone and cyclohexanol. At the end of the session (from 460 min course time), cyclohexanone and cyclohexanol concentrations became stable, suggesting that physical adsorption equilibrium had been reached. Since there was still cyclohexanone and cyclohexanol existent, we conclude that no chemical reactions are responsible for the decrease in products, but physical adsorption is the cause.

Furthermore, Carneiro et al. [18] have shown that humidified gas enhances desorption of cyclohexanone from anatase titania Solaronix "S450", in both dark and illuminated conditions. Renckens et al. [16] showed desorption of cyclohexanone from Hombikat Uv100 in the dark as well. Almquist and Biswas [19] observed increased cyclohexanone production under illumination for humidified gas flows, and attribute this among other things to increased desorption of products.

We therefore propose that adsorption of water onto the titania surface results in desorption of the reaction products cyclohexanone and cyclohexanol. We assume that one type of active site is involved in both the production of cyclohexanone and cyclohexanol. It is known that the rate of photocatalytic oxidation depends directly on the concentrations of oxygen and the reactant, not on the concentrations of the oxidation products [43]. However, adsorbed cyclohexanone and cyclohexanol can get oxidised further towards carbon dioxide; "deep oxidation". The rate of deep oxidation of cyclohexanol and cyclohexanone will depend on the concentration of respectively adsorbed cyc- lohexanol and cyclohexanone.

Thus, increasing humidity leads to decreasing surface occupancy of reaction products, probably decreasing the rate of deep oxidation of cyclohexanone and cyclohexanol. This results in increasing apparent production rates of bulk cyclohexanone and cyclohexanol as observed in Figure 10.

\subsubsection{Transient rates and limitations}

In view of the above transients in adsorption behaviour, apparently depending on the illumination history of the monolith, determining the effect of humidity on production rate is far from trivial. We have attempted to derive such correlations in Figure 10. Solid symbols denote stable rates (for example the rate observed for session 19 after 120 minutes, in Figure 8), while open symbols represent transient rates, circles representing higher rates observed when changing humidity from low to high values (for example the initial rate of session 19 in Figure 8), and squares the opposite change from high to low values of humidity. As shown in Figure 10 this transient leads to significant adsorption of the products, in some cases even leading to apparent negative production rates (up to $40 \%$ of humidity).

The arrow pointing downwards at $40 \%$ relative humidity $(\mathrm{RH})$ in Figure 10 indicates that when increasing the humidity from $<40 \%$ to $40 \%$ during an experiment, initially a cyclohexanone production rate of around $8 \cdot 10^{-6} \mathrm{~mol} \mathrm{~h}^{-1}$ (open circle) is obtained, changing to a stable cyclohexanone production rate of $3 \cdot 10^{-6} \mathrm{~mol} \mathrm{~h}^{-1}$ (solid diamonds). The arrow pointing upwards indicates the reverse observation: decreasing humidity from $>$ 


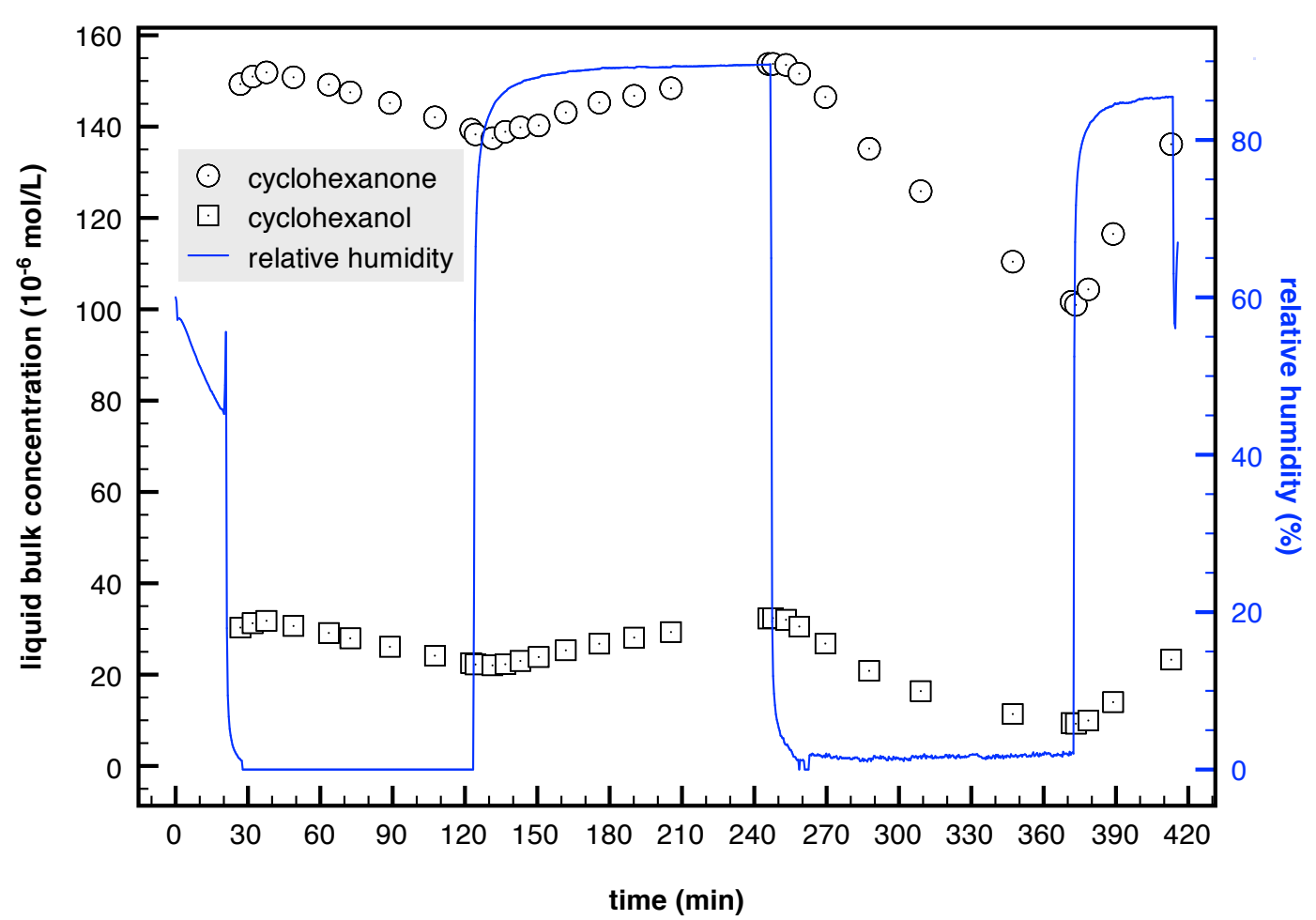

Figure 9: Liquid bulk concentrations of cyclohexanone and cyclohexanol (left vertical axis) versus course of time of a session conducted using the IIMR for alternating humidities (blue line, right vertical axis) without illumination.

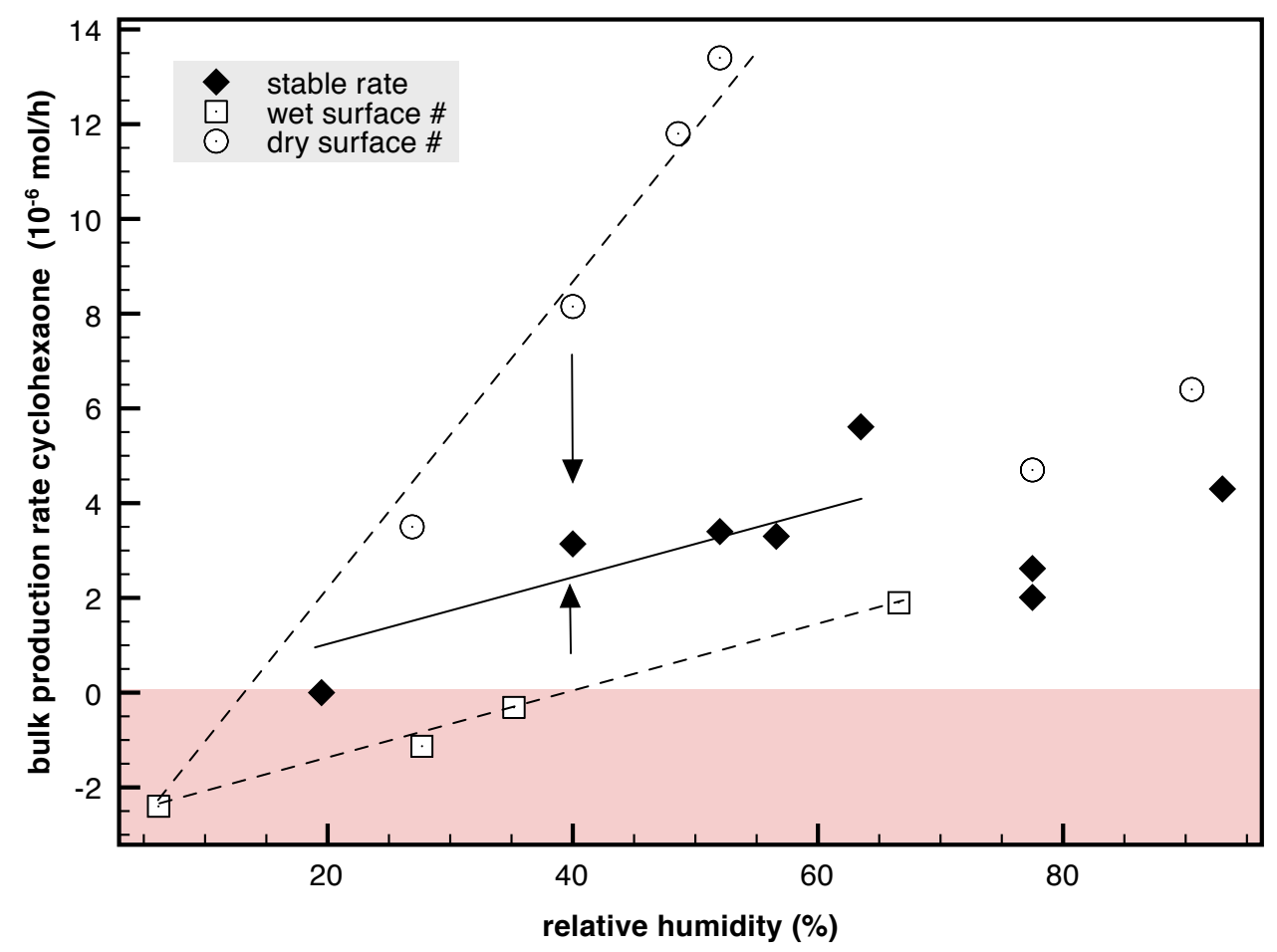

Figure 10: Liquid bulk production rates of cyclohexanone (corrected for evaporation of cyclohexane) versus relative humidity.

Solid diamonds represent stable bulk cyclohexanone production rates (left vertical axis). All open symbols (also denoted with a hash \# in the legend) denote transient rates. Open squares indicate that the titania surface is expected to be highly occupied with water. Open circles denote a presumably low surface occupation of water. The lightly red-coloured area represents negative production rates (consumption from the liquid bulk). The three manually drawn lines are for visibility purposes only. The lines connecting solid diamonds and open squares are of exactly the same slope. The two arrows represent the transient character of the open symbols connected by the dashed lines. 


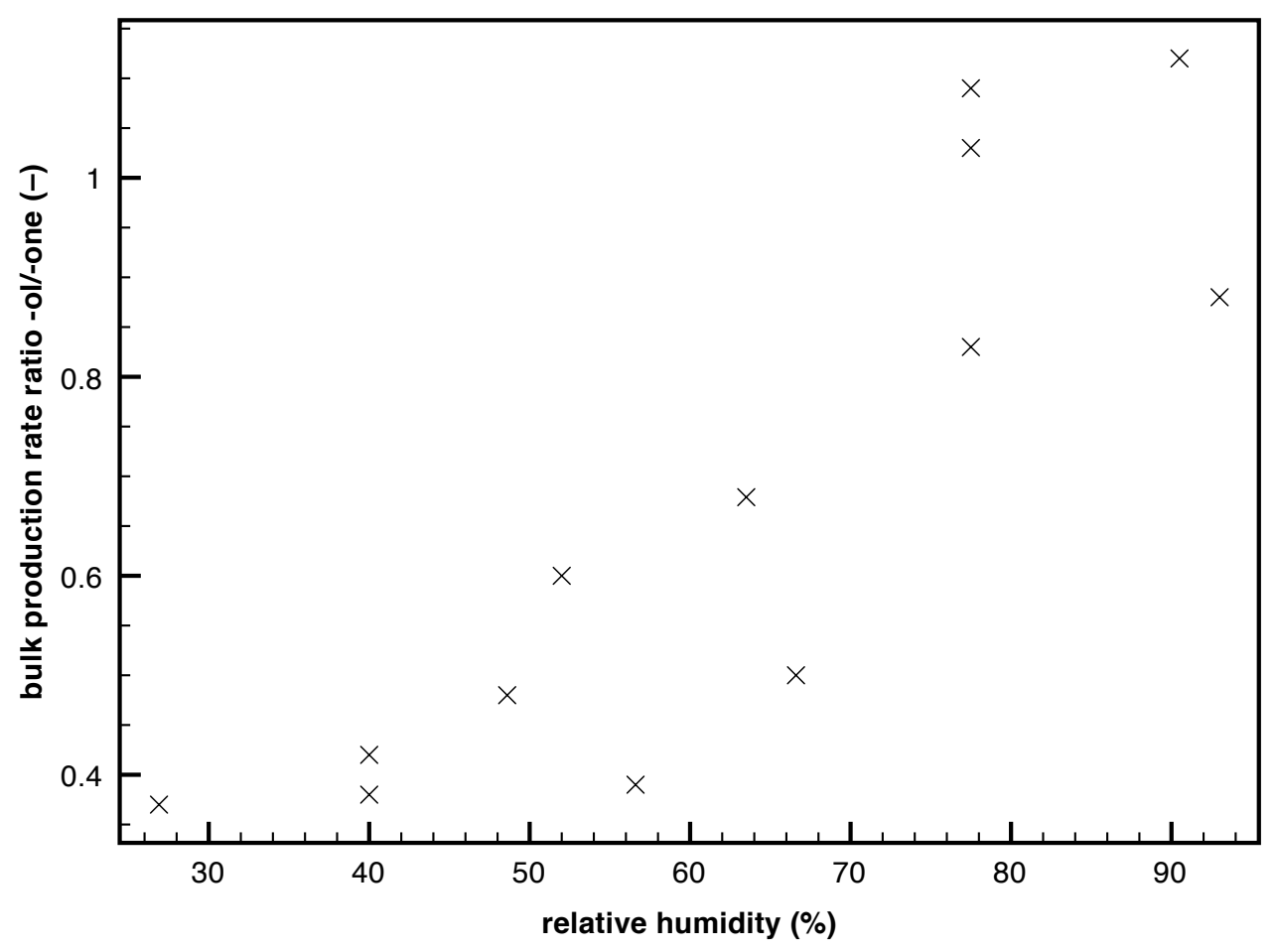

Figure 11: Liquid bulk production rate of cyclohexanol divided by that of cyclohexanone versus relative humidity. Production rate ratios of negative rates are not shown.

$40 \%$ to $40 \%$ initially yields a cyclohexanone production rate of around $0 \mathrm{~mol} \mathrm{~h}^{-1}$, slowly changing to a steady state cyclohexanone production rate of $3 \cdot 10^{-6} \mathrm{~mol} \mathrm{~h}^{-1}$ (solid diamond).

We explain this behaviour as follows. During the oversaturated state of the monolith, water desorbs from the $\mathrm{TiO}_{2}$ surface. Desorption of water liberates sites on which cyclohexanone can be adsorbed, temporarily decreasing liquid bulk cyclohexanone production. When adsorption equilibria have been reached, the cyclohexanone production rate has returned to the solid line connecting the solid diamonds. The same reasoning applies to a monolith that was previously applied in less humid conditions (Figure 10: open circles). A temporary increase in apparent production rates is caused by increased desorption of products, due to adsorption of water.

For $\mathrm{RH}>70 \%$ a deviation from the linearity in activity increase can be observed. From the five rates at RH $>70 \%$, the lowest three are stable production rates. The two highest rates (open circles) were only observed for one hour or less, at the start of an experiment. We think that for equilibrium at $\mathrm{RH}>$ $70 \%$, the relatively small number of free sites due to adsorbed water negatively affects the steady-state liquid bulk production rate of cyclohexanone.

Having significant (multilayer) occupation of water on the surface might also have consequences for $\mathrm{O}_{2}$ availability, as follows. Physical solubility of oxygen in cyclohexane is almost fifty times larger than oxygen solubility in water at $20^{\circ} \mathrm{C}$ [44]. Thus, another explanation for the decreased rates for $\mathrm{RH}>70 \%$ is that the uptake of oxygen by titania is faster for a comparatively dry surface in direct contact with cyclohexane, than for a titania surface with a high water occupancy.

\subsubsection{Cyclohexanol production and selectivity}

Cyclohexanol was not produced in observable quantities under dry conditions. In humid conditions, the cyclohexanol concentration rose more for increasing humidity than the cyclohexanone concentration shown in Figure 8 (session 19). This unfortunately leads to a decreased selectivity towards cyclohexanone in humidified conditions as compared to dry conditions.

Carneiro et al. [18] obtained the same type of results for illumination of Solaronix "S450" powder in a top illuminated slurry reactor (TIR): humidified gas flow yielded sustainable bulk production of cyclohexanone and cyclohexanol while dry gas flow did not yield cyclohexanol.

For positive production rates, the ratio of cyclohexanol divided by the cyclohexanone production rate is plotted in Figure 11. Although scattered data are obtained, the trend is obvious: cyclohexanone selectivity is lower in humidified conditions. The ratio of cyclohexanol production rate divided by cyclohexanone rate increases from 0.4 to 1.0 as a function of increasing humidity from $30 \%$ to $90 \%$. We propose two causes for this:

1. an increase in hydroxyl radical concentration

2. prevention of deep oxidation of cyclohexanol by, as compared to cyclohexanone, a larger extent of increased desorption

The following two sections discuss these two explanations.

Hydroxyl radicals. Hydroxyl radical formation can be enhanced at increased levels of water vapour [45]. The increase in reaction rate of cyclohexane with these hydroxyl radicals might 
lead to an increase in cyclohexyl radical concentration. Thus, the rates of formation of both cyclohexanone and cyclohexanol will increase.

Furthermore, hydroxyl radicals can readily react with cyclohexyl radicals, forming cyclohexanol [19]. Since formation of cyclohexanol is second order-dependent, and assuming first order dependency of cyclohexanone formation on hydroxyl radical concentration, the rate of cyclohexanol formation will increase comparatively stronger than the formation rate of cyclohexanone. Therefore, increased availability of hydroxyl radicals leads to an increase in cyclohexanol/cyclohexanone production rate ratio, as observed (Figure 11).

Prevention of deep oxidation of cyclohexanol. Increasing humidity can also lead to non-proportionally decreasing concentrations of adsorbed compounds as a result of different adsorption equilibrium constants. Adsorbed cyclohexanone and cyclohexanol can get oxidised further towards carbon dioxide; "deep oxidation". The rate of deep oxidation of cyclohexanol and cyclohexanone will depend on the concentration of respectively adsorbed cyclohexanol and cyclohexanone. When the concentrations of adsorbed cyclohexanone and cyclohexanol decrease non-proportionally as a result of increasing humidity, the loss of cyclohexanol and cyclohexanone due to deep oxidation will decrease non-proportionally too. This can result in a decrease in apparent selectivity towards cyclohexanone (Figure 11). This is in agreement with previous results [18].

Boarini et al. [21] demonstrate that addition of a polar solvent such as dichloromethane yields more cyclohexanol, and less carbon dioxide. Unfortunately, due to the low conversion values, analysis of the gas effluent for $\mathrm{CO}_{2}$ is difficult. This is necessary to support the hypothesis that deep oxidation of cyclohexanol is prevented by competitive adsorption of water.

\subsection{Uv-induced regeneration}

Carneiro et al. [18] show by attenuated total reflectance Fourier transform infrared spectroscopy (ATR-FTIR) that adsorbed carboxylates and carbonates accumulate on the surface of anatase titania Hombikat uv100 and Solaronix "S450" during irradiation at dry conditions. Carboxylates decrease the photocatalytic activity of $\mathrm{TiO}_{2}$ [15].

Hydroxyl radicals are thought to oxidise organics that are (irreversibly) adsorbed on the photocatalyst [46, 47]. Humidified air at illuminated conditions adds to the quantity of hydroxyl radicals on titania [45]. Humid air without illumination does not remove carboxylates and carbonates from the titania surface, only after switching on the light these are removed [18]. Hydroxyl radicals probably oxidise carboxylates and carbonates to carbon dioxide; Ameen and Raupp [47] for example detected that water vapour converts adsorbed species involved in photocatalytic gas-phase $o$-xylene degradation into carbon dioxide, which can be explained by hydroxyl radicals. Einaga et al. [46] observed similar results for the photocatalysed oxidation of gaseous benzene.

We illuminated a deactivated monolith under $91 \%$ humid gas flow for one hour, thus exposing the $\mathrm{TiO}_{2}$ surface to hydroxyl radicals (without cyclohexane). Unfortunately, produc- tion of cyclohexanone under dry illuminated conditions directly after this regeneration attempt was not observed. Similar experiments in the presence of liquid cyclohexane showed no regenerative effect for activity under dry conditions either.

We conclude that photocatalytic oxidation products such as cyclohexanone, cyclohexanol, carboxylates and carbonates could not be removed adequately from the titania surface using combined illumination and humid gas flow, in order to restore activity of the monolith under dry conditions. It could be that our irradiance (Section 2.2) is too little intense to generate enough hydroxyl radicals to achieve monolith 'cleaning'. This is subject of further research in our laboratory.

\subsection{Photocatalytic efficiency}

A measure of the performance of a photocatalytic process is the photonic efficiency. In the present study, the production of cyclohexanone divided by the amount of photons, is $17 \%$ (at a relative humidity $65 \%$ ). This is a significant number, and indicates that transfer of charge carrier states (electrons and holes) to the adsorbed molecules (cyclohexane, water, and oxygen) is relatively fast.

Still, the observed rates in cyclohexanone production are quite small, and large reaction times are needed to obtain significant quantitative yields of cyclohexanone. Dimming the irradiance of all fibres results in a lower bulk cyclohexanone production rate; the performance of the IIMR is limited by irradiance. One of the limiting factors in photocatalysis in general is the ability to expose the catalytic sites to sufficient light. While the geometry of a monolith is favourable to enhancing catalytic rates, the optical fibres used in the present study are capable of only emitting small quantities of light. Manipulation of the fibres is necessary to increase the emission. We expect that if irradiance is increased by a factor $1.2 \cdot 10^{4}$ to at least $2.3 \mathrm{~mol} \mathrm{~h}^{-1} \mathrm{~m}^{-2}$, significant improvements in performance can be obtained. This value (assuming photons of $300 \mathrm{~nm}$ ) corresponds to the maximum for linear dependency of reaction rate on irradiance, albeit determined in slurry reactors [43].

\section{Conclusions}

Aim of this work was to determine the performance of the IIMR equipped with titania Hombikat Uv100 in the photocatalytic oxidation of liquid cyclohexane to cyclohexanone. The influence of water vapour on the performance was investigated.

Operating the IIMR in a dry gas flow leads to deactivation. Activity can be restored by heating the monolith at temperatures of $450{ }^{\circ} \mathrm{C}$ in air.

Deactivation was not observed when operating the IIMR using humid gas flow ( $\mathrm{RH}>20 \%$ ), probably explained by enhanced desorption of the products from the catalyst surface, thus preventing consecutive oxidation to surface deactivating species.

Cyclohexanone production increases linearly with increasing relative humidity. Production of cyclohexanol appears to benefit stronger from humidity as compared to cyclohexanone, which can be the consequence of a concentration of hydroxyl 
radicals in humid conditions, as well as by preferred desorption from the $\mathrm{TiO}_{2}$ surface.

Hydroxyl radicals were not found to regenerate the catalyst for cyclohexane oxidation.

\section{Acknowledgements}

Many thanks to Robert Meijer for the fruitful discussions and modifications to experimental setups. Thanks to Emiel Kappert and Rob Lammertink for proofreading of the manuscript.

\section{Appendix A. Illumination}

\section{Appendix A.1. Spectrum plot lamp $\mathrm{HP} 100$}

Figure A.12 shows a qualitative spectrum of the light irradiating from the lamp used in this work.

\section{Appendix B. Liquid bulk concentration determination}

\section{Appendix B.1. Gc response factor determination}

It was verified regularly whether the GC response factors had changed by redoing GC analysis of standard samples. EzChrom Elite Compact 3.3.2 sp2 software from Agilent performed the integration of peak areas for all solutions.

Resulting peak areas of cyclohexanol, cyclohexanone and hexadecane for the standard solutions were plotted versus concentration and linearly regressed. Average relative standard uncertainty in standard solution preparation $u_{\mathrm{sp}}^{\prime}$ was estimated for all solutions, the biggest uncertainty obtained was used in further calculations for sake of simplicity. Standard deviations $s_{\mathrm{lr}}$ arising from linear regression were calculated. Uncertainties $u_{\mathrm{sp}}^{\prime}$ and $s_{\mathrm{lr}}$ lead to a confidence interval for future samples of unknown concentration, see [42] for more information.

\section{Appendix B.2. Analysis of samples}

Randomisation of the analysis order ensures that possible trends in analysis deviations will not enhance experimental trends, but will result in random effects. Resulting peak surface areas of each duplicate were compared, a third GC analysis was performed when two areas of a duplicate differed significantly more than the average difference of other samples. Such a third (or even fourth or fifth) GC analysis of a certain sample pointed which determined peak area(s) is/are the outlier(s). Outliers were neglected in further calculations. The average peak surface area of each duplicate was used in further calculations. Note that the duplicates were not used to estimate the random error in peak surface areas.

To minimise confidence intervals of IIMR sample concentrations, the linear regression done in $\mathrm{GC}$ response factor determination for standard solutions (see Section Appendix B.1) was redone for each IIMR experiment. Only standard solutions covering the $\mathrm{GC}$ peak area range of zero up to the experiment's maximum peak area were used in the regression, to minimise standard deviation $s_{\mathrm{lr}}$ originating from linear regression.

\section{Appendix B.3. Calculation of reactor concentrations}

The liquid concentrations of cyclohexanone, cyclohexanol and hexadecane contained by the IIMR were determined using GC analysis of the liquid samples. It was assumed that hexadecane does not evaporate from the reactor liquid due to its low vapour pressure $\left(<7 \cdot 10^{-6}\right.$ bar versus 0.10 bar for cyclohexane at 20 $\left.{ }^{\circ} \mathrm{C}\right)$. Thus, from the increase in concentration of hexadecane

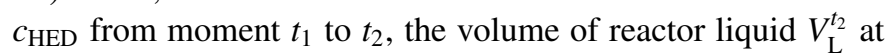
time $t_{2}$ can be calculated when the volume at time $t_{1}$ is known:

$$
V_{\mathrm{L}}^{t_{2}}=\frac{V_{\mathrm{L}}^{t_{1}} c_{\mathrm{HED}}^{t_{1}}}{c_{\mathrm{HED}}^{t_{2}}}
$$

Vapour pressure of cyclohexanone and cyclohexanol are respectively $3 \%$ and $1 \%$ of the vapour pressure of cyclohexane at $20{ }^{\circ} \mathrm{C}$. Therefore, cyclohexanone and cyclohexanol were assumed not to evaporate from the reactor liquid. Measured concentrations of cyclohexanone and cyclohexanol $c_{m}$ were converted to hypothetical concentrations $c_{h}$ :

$$
c_{h}=\frac{c_{m} V_{\mathrm{L}}^{t_{2}}}{V_{\mathrm{L}}^{t_{1}}}
$$

Combination of both equations yields:

$$
c_{h}=\frac{c_{m} c_{\mathrm{HED}}^{t_{1}}}{c_{\mathrm{HED}}^{t_{2}}}
$$

For most reactor sessions the trend in increase of hexadecane concentration was close in size to the random error in hexadecane concentration. Therefore, hexadecane concentration data were linearly regressed before using the data for the correction for evaporation of cyclohexanone and cyclohexanol concentrations.

Note that the rates were calculated by multiplying with the volume that was poured into the reactor setup. This volume might have actually decreased somewhat due to evaporation during the pre-saturation time. On the other hand, the actual liquid reactor volume might have been somewhat higher due to liquid volume that was already contained by the reactor in dead volume spaces. Since these two effects weaken each other and are considered minor, no correction was applied for these effects.

Each liquid sample for GC analysis is about $1 \mathrm{~mL}$. Since the total amount of samples taken is small compared to total reactor volume (around $1.5 \%$ ), the decrease in reactor volume from sampling was neglected in calculations.

\section{References}

[1] O. Carp, C. L. Huisman, A. Reller, Progress in Solid State Chemistry 32 (2004) 33-177. URL: http://dx.doi.org/10.1016/j.progsolidstchem.2004.08.001.

[2] A. Fujishima, X. Zhang, D. A. Tryk, Surface Science Reports 63 (2008) 515-582. URL: http://dx.doi.org/10.1016/j.surfrep.2008.10.001. 


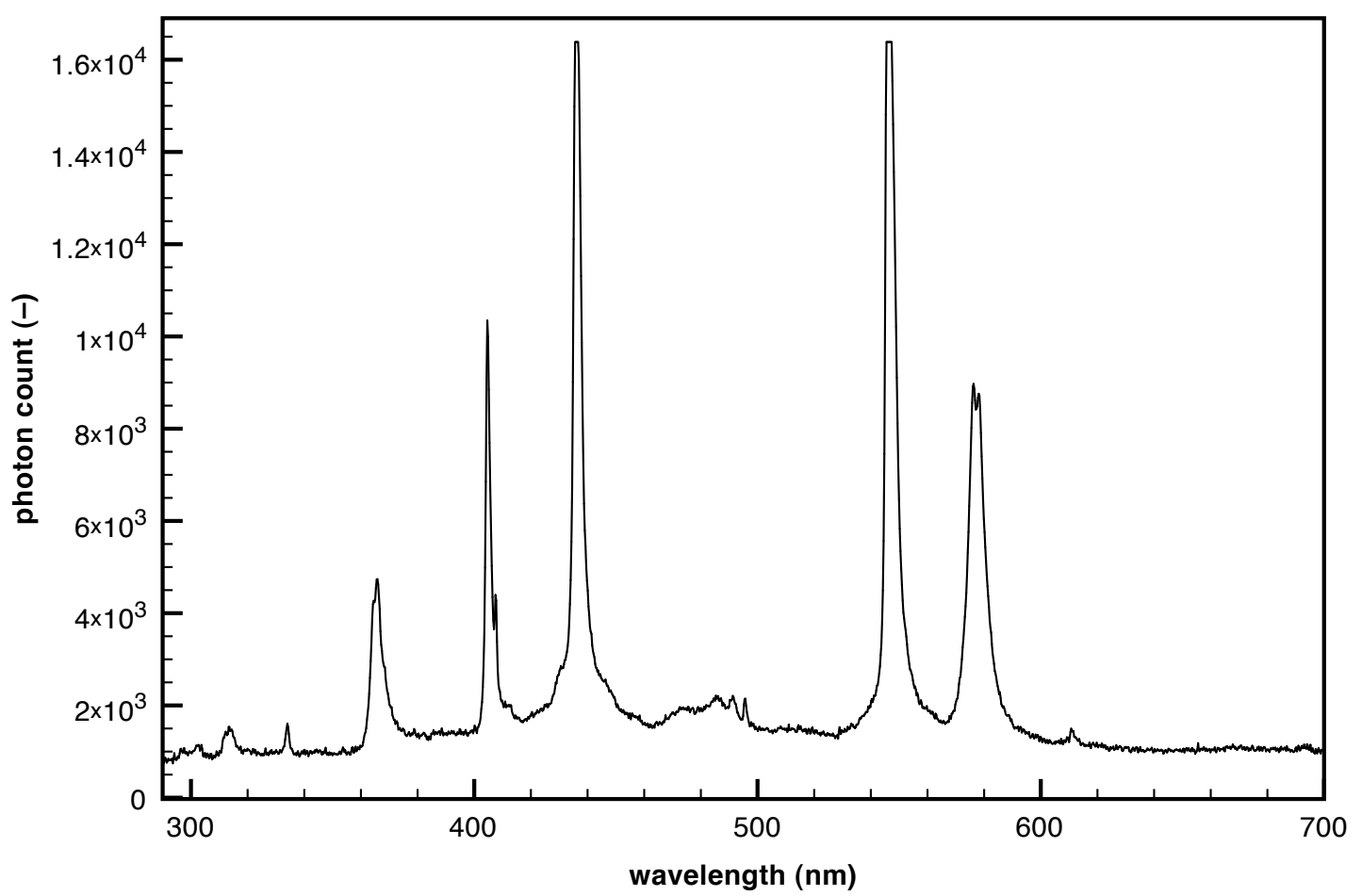

Figure A.12: Photon count as a function of wavelength (300-700 nm) of the light exiting the mercury lamp system Dr. Gröbel HP100. The photon count from 700 until $1100 \mathrm{~nm}$ was negligible and is therefore not shown. This spectrum plot was determined using a photospectrometer HR4000 from Ocean Optics.

[3] M. A. Henderson, Surface Science Reports 66 (2011) 185-297. URL: http://dx.doi.org/10.1016/j.surfrep.2011.01.001.

[4] A. L. Linsebigler, G. Lu, J. T. Yates, Chemical Reviews 95 (1995) 735758. URL: http://dx.doi.org/10.1021/cr00035a013.

[5] M. T. Musser, Ullmann's Encyclopedia of Industrial Chemistry, Wiley-VCH Verlag $\mathrm{GmbH}, 2000$, pp. 1-12. URL: http://dx.doi.org/10.1002/14356007.a08_217.

[6] M. D. Hernández-Alonso, A. R. Almeida, J. A. Moulijn, G. Mul, Catalysis Today 143 (2009) 326-333. URL: http://dx.doi.org/10.1016/j.cattod.2008.09.025.

[7] R. Vinu, G. Madras, Applied Catalysis A: General 366 (2009) 130-140. URL: http://dx.doi.org/10.1016/j.apcata.2009.06.048.

[8] J. T. Carneiro, T. J. Savenije, J. A. Moulijn, G. Mul, Journal of Photochemistry and Photobiology A: Chemistry 217 (2011) 326-332. URL: http://dx.doi.org/10.1016/j.jphotochem.2010.10.027.

[9] A. R. Almeida, J. T. Carneiro, J. A. Moulijn, G. Mul, Journal of Catalysis 273 (2010) 116-124. URL: http://dx.doi.org/10.1016/j.jcat.2010.05.006.

[10] E. Sahle-Demessie, M. Gonzalez, Z.-M. Wang, P. Biswas, Industrial \& Engineering Chemistry Research 38 (1999) 3276-3284. URL: http://dx.doi.org/10.1021/ie990054l.

[11] E. Polo, R. Amadelli, V. Carassiti, A. Maldotti, J. B. M. Guisnet, Photocatalytic Oxygenation of Hydrocarbons on TiO2/Iron-Porphyrin Hybrid Catalysts, volume Volume 78, Elsevier, 1993, pp. 409-416. URL: http://dx.doi .org/10.1016/S0167-2991 (08)63347-9.

[12] A. Maldotti, A. Molinari, R. Amadelli, E. Carbonell, H. Garcia, Photochemical \& Photobiological Sciences 7 (2008) 819-819. URL: http://dx.doi.org/10.1039/b804377a.

[13] X. Li, G. Chen, Y. Po-Lock, C. Kutal, Journal of Chemical Technology \& Biotechnology 78 (2003) 1246-1251. URL: http://dx.doi.org/10.1002/jctb. 872.

[14] J. T. Carneiro, A. R. Almeida, J. A. Moulijn, G. Mul, Physical Chemistry Chemical Physics 12 (2010) 2744-2744. URL: http://dx.doi.org/10.1039/b919886e.

[15] P. Du, J. A. Moulijn, G. Mul, Journal of Catalysis 238 (2006) 342-352. URL: http://dx.doi.org/10.1016/j.jcat.2005.12.011.

[16] T. J. A. Renckens, A. R. Almeida, M. R. Damen, M. T.
Kreutzer, G. Mul, Catalysis Today 155 (2010) 302-310. URL: http://dx.doi.org/10.1016/j.cattod.2009.12.002.

[17] A. R. Almeida, M. Calatayud-Antonino, F. Tielens, J. A. Moulijn, G. Mul, The Journal of Physical Chemistry C 115 (2011) 14164-14172. URL: http://dx.doi.org/10.1021/jp1122129.

[18] J. T. Carneiro, C.-C. Yang, J. A. Moulijn, G. Mul, Journal of Catalysis 277 (2011) 129-133. URL: http://dx.doi.org/10.1016/j.jcat.2010.10.019.

[19] C. B. Almquist, P. Biswas, Applied Catalysis A: General 214 (2001) 259-271. URL: http://dx.doi.org/10.1016/S0926-860X (01) 00495-1.

[20] M. A. Brusa, Y. Di Iorio, M. S. Churio, M. A. Grela, Journal of Molecular Catalysis A: Chemical 268 (2007) 29-35. URL: http://dx.doi.org/10.1016/j.molcata.2006.12.008.

[21] P. Boarini, V. Carassiti, A. Maldotti, R. Amadelli, Langmuir 14 (1998) 2080-2085. URL: http://dx.doi.org/10.1021/1a970384f.

[22] J. T. Carneiro, J. A. Moulijn, G. Mul, Journal of Catalysis 273 (2010) 199-210. URL: http://dx.doi.org/10.1016/j.jcat.2010.05.015.

[23] A. R. Almeida, R. Berger, J. A. Moulijn, G. Mul, Physical Chemistry Chemical Physics 13 (2011) 1345-1345. URL: http://dx.doi.org/10.1039/c0cp00879f.

[24] M. A. Brusa, M. A. Grela, The Journal of Physical Chemistry B 109 (2005) 1914-1918. URL: http://dx .doi .org/10.1021/jp045602+.

[25] T. Van Gerven, G. Mul, J. Moulijn, A. Stankiewicz, Chemical Engineering and Processing 46 (2007) 781-789. URL: http://dx.doi.org/10.1016/j.cep.2007.05.012.

[26] A. R. Almeida, J. A. Moulijn, G. Mul, The Journal of Physical Chemistry C 115 (2011) 1330-1338. URL: http://dx.doi.org/10.1021/jp107290r.

[27] A. R. Almeida, J. A. Moulijn, G. Mul, The Journal of Physical Chemistry C 112 (2008) 1552-1561. URL: http://dx.doi.org/10.1021/jp077143t.

[28] P. Du, J. T. Carneiro, J. A. Moulijn, G. Mul, Applied Catalysis A: General 334 (2008) 119-128. URL: http://dx.doi.org/10.1016/j.apcata.2007.09.045.

[29] R. Portela, B. Sánchez, J. M. Coronado, R. Candal, 
S. Suárez, Catalysis Today 129 (2007) 223-230. URL: http://dx.doi.org/10.1016/j.cattod.2007.08.005.

[30] R. Portela, S. Suárez, R. F. Tessinari, M. D. Hernández-Alonso, M. C. Canela, B. Sánchez, Applied Catalysis B: Environmental 105 (2011) 95102. URL: http://dx.doi.org/10.1016/j.apcatb.2011.03.039.

[31] I. J. Ochuma, O. O. Osibo, R. P. Fishwick, S. Pollington, A. Wagland, J. Wood, J. M. Winterbottom, Catalysis Today 128 (2007) 100-107. URL: http://dx.doi.org/10.1016/j.cattod.2007.05.015.

[32] H. Lin, K. T. Valsaraj, Journal of Applied Electrochemistry 35 (2005) 699-708. URL: http://dx.doi.org/10.1007/s10800-005-1364-x.

[33] R.-D. Sun, A. Nakajima, I. Watanabe, T. Watanabe, K. Hashimoto, Journal of Photochemistry and Photobiology A: Chemistry 136 (2000) 111-116. URL: http://dx.doi.org/10.1016/S1010-6030(00)00330-0.

[34] W. Choi, J. Y. Ko, H. Park, J. S. Chung, Applied Catalysis B: Environmental 31 (2001) 209-220. URL: http://dx.doi.org/10.1016/S0926-3373(00) 00281-2.

[35] A. Danion, J. Disdier, C. Guillard, N. Jaffrezic-Renault, Journal of Photochemistry and Photobiology A: Chemistry 190 (2007) 135-140. URL: http://dx.doi.org/10.1016/j.jphotochem.2007.03.022.

[36] J. C. S. Wu, H.-M. Lin, C.-L. Lai, Applied Catalysis A: General 296 (2005) 194-200. URL: http://dx.doi.org/10.1016/j.apcata.2005.08.021.

[37] M. Ren, K. T. Valsaraj, Separation and Purification Technology $62 \quad$ (2008) 523-528. URL: http://dx.doi.org/10.1016/j.seppur.2008.02.029.

[38] G. B. Raupp, A. Alexiadis, M. M. Hossain, R. Changrani, Catalysis Today 69 (2001) 41-49. URL: http://dx.doi.org/10.1016/S0920-5861(01)00353-4.

[39] M. L. Sauer, D. F. Ollis, Journal of Catalysis 158 (1996) 570-582. URL: http://dx.doi.org/10.1006/jcat.1996.0055.

[40] L. Zhong, F. Haghighat, Chemical Engineering Science 66 (2011) 59455954. URL: http://dx.doi.org/10.1016/j.ces.2011.08.017.

[41] M. Furman, S. Corbel, H. Le Gall, O. Zahraa, M. Bouchy, Chemical Engineering Science 62 (2007) 5312-5316. URL: http://dx.doi.org/10.1016/j.ces.2006.12.045.

[42] V. H. A. van Dijk, The influence of water vapour on the photocatalytic oxidation of cyclohexane in an internally illuminated monolith reactor, Master's thesis, University of Twente, 2011. URL: http://purl.utwente.nl/essays/61198.

[43] J.-M. Herrmann, Catalysis Today 53 (1999) 115-129. URL: http://dx.doi.org/10.1016/S0920-5861 (99)00107-8.

[44] T. R. R. Rubin Battino, T. Tominaga, Journal of Physical and Chemical Reference Data 12 (1983) 163-178. URL: http://www.nist.gov/data/PDFfiles/jpcrd219.pdf. doi:10.1063/1.555680.

[45] S. Sun, J. Ding, J. Bao, C. Gao, Z. Qi, C. Li, Catalysis Letters 137 (2010) 239-246. URL: http://dx.doi.org/10.1007/s10562-010-0358-4, 10.1007/s10562-010-0358-4.

[46] H. Einaga, S. Futamura, T. Ibusuki, Physical Chemistry Chemical Physics 1 (1999) 4903-4908. URL: http://dx.doi.org/10.1039/a906214i.

[47] M. M. Ameen, G. B. Raupp, Journal of Catalysis 184 (1999) 112-122. URL: http://dx.doi.org/10.1006/jcat.1999.2442. 